\title{
Studies on biological control potential of Steinernema abbasi CS-39 against Helicoverpa armigera (Hub.) (Lepidoptera: Noctuidae) by adopting the regression probit model
}

\author{
Shreyansh Srivastava* ${ }^{*}$, Heena $\mathbb{0}$ and Ashok Kumar Chaubey
}

\begin{abstract}
Background: In India, application of entomopathogenic nematodes (EPNs) as a bio-agent against insect pests was known since 5-6 decades with the application of the exotic species Steinernema carpocapsae (DD-136 Strain). EPNs have a strong potential to control the soil-borne insect pests. In the present study isolated strain was identified as Steinernema abbasi and docketed as CS-39. The efficacy of the isolated strain was tested against the American bollworm, Helicoverpa armigera (Hub.) (Lepidoptera: Noctuidae).

Results: Laboratory bioassay revealed that the median lethal concentration $\left(\mathrm{LC}_{50}=83.21 \mathrm{IJs}\right)$ of the $\mathrm{S}$. abbasi isolate CS-39 was quite sufficient to achieve 100\% mortality after $24 \mathrm{~h}$ of exposure. Mean mortality percentage was estimated $>75 \%$ at all concentrations, i.e., 25, 50, 100 and $200 \mathrm{IJs} /$ larva, and 100\% mortality was achieved at $200 \mathrm{lJs} /$ larva after $24 \mathrm{~h}$ of concentration exposure. Positive relationship was found at every concentration of exposure and $\%$ mortality of the insect pest ( $H$. armigera) after $36(p<0.01)$ and $48 \mathrm{~h}$ of exposure $(p<0.02)$.

Conclusions: Steinernema abbasi isolate CS-39 found to be highly virulent to $H$. armigera. As the result urged, $200 \mathrm{lJs}$ / larva showed 100\% mortality at $36 \mathrm{~h}$, whereas $100 \mathrm{lJs}$ / larva showed 100\% mortality at $60 \mathrm{~h}$. Difference in time duration might be because of action of bacterial symbionts which were the main precursor of pathogenicity. Extensive study of secondary metabolites of the bacterial symbionts may extend the present study to the new dimension.
\end{abstract}

Keywords: Entomopathogenic nematode, Steinernema abbasi, Helicoverpa armigera, Pathogenicity, Virulence

\section{Background}

Cotton bollworm, the heliothine species Helicoverpa armigera (Hubner) (Lepidoptera: Noctuidae), is one of the world's most economic agricultural pest. It can feed and complete its life cycle on more than 180 plant species (Tay et al. 2013). Economic thresholds are usually lower for heliothines compared with other defoliators (Stacke et al. 2018). H. armigera is polyphagous (Tay et al. 2013). The excessive use of chemical pesticides in

\footnotetext{
*Correspondence: shreyanshsrivastava04@gmail.com Nematology Laboratory, Department of Zoology, Chaudhary Charan Singh University, Meerut 250004, India
}

agriculture causes serious damage to soil, air, water, flora, fauna and human beings (Vos et al. 2000) and of course development of resistance in the concern insect pest. Therefore, it is necessary to develop environmentally friendly alternatives (biological control) to control such soil-borne pests. Biological control is the safest side which may include bacteria, viruses, fungi and nematodes as biological insecticides. Among them, nematodes are the most numerous multicellular animals on earth. Some of the nematodes have a symbiotic association with insect pathogenic bacteria and ability to kill insect pests within a very short period. Such nematodes are called as entomopathogenic nematodes (EPNs) which belong 
to families Steinernematidae and Heterorhabditidae are lethal obligatory parasites of insects.

Worldwide, the prevalence of EPNs reported to range from 0.7 to $50 \%$ in soil samples (Benseddiq et al. 2020). The range may be exceeded through repeated extraction technique and with different sampling methods (Abd-Elgawad 2021). Recently, Abd-Elgawad (2021) has reviewed the strength and shortcomings of nematodesampling and extraction methods. EPNs exist in many habitats and have a wide range of tolerance to abiotic and biotic parameters (Grewal et al. 1994). Infective stage of these nematodes is third-stage infective juveniles (IJs) that are the only life stage typically found outside the host cadaver, which are non-feeding, resistant to environmental stress and are normally called as dauer larvae. These non-feeding IJs of Steinernema locate host and enter into the hemocoel through natural openings like mouth, anus and respiratory spiracles. IJs after reaching upon the hemocoel, ultimately release symbiotic bacteria into the insect hemocoel. This symbiotic bacterium releases insect toxins, exoenzymes and other metabolites to kill the insect host by septicemia within 24 to $48 \mathrm{~h}$ after infection. Released bacterial symbionts digest the host tissues and provide suitable nutrient and environment for nematode growth and development (Dillman et al. 2012). The bacteria propagate and protect the cadaver from colonization by other micro-organisms also. EPNs play an indispensible role as a biological control agent in the field of agriculture for the management of major insect pests (Yuksel and Canhilal 2018 and Majić et al. 2019). It is the very reason that there has been a tremendous scientific interest in both obtaining EPNs and determining their efficacy against the most damaging species (Canhilal et al. 2016 and Kepenekci et al. 2018).

Estimation of $\mathrm{LC}_{50}$ is a relative measure of perceptivity of a host population and is convenient and commonly used index of relative efficiency (Epsky and Capinera 1994). For any biological control program, virulence against the target pest is considered as the most prominent factor. In screening EPNs as potential candidate against insect pests, probit regression model can be of a great value as suggested by Cabanillas and Roulston (1994). The significance of this model is that it describes not only the statistical relationship between the insect mortality response and the nematode concentration but also provides a value for the slope which estimates the change in activity or pathogenicity per unit change in concentration of nematodes. H. armigera cannot be controlled by insecticides alone even after the repeatedly use of them because of its rapid resistivity against the insecticide, particularly in cotton and vegetable fields. Obviously, once resistance develops, that active ingredient will likely fail to control $\mathrm{H}$. armigera in agricultural crops of the same geographical area, minimizing the choices of products available to manage this pest. Hence, an attempt was made to identify and investigate the virulence of the present EPN isolate CS-39 at different concentrations against $H$. armigera under laboratory conditions adopting regression probit model.

\section{Methods \\ Maintenance of $\mathrm{H}$. armigera in laboratory}

Eggs of $H$. armigera were purchased from ICAR National Bureau of Agriculturally Important Insects (NBAII), Bangalore (National Accession No. F.NBAII/PME-03/2020 21/7177), and reared in the laboratory on chickpea-based diet as described by Nagarkatti and Prakash (1974), modified by Kalia et al. (2001). The larvae reared were transferred to 12-well plates containing a small piece of semi-synthetic diet. The 4th larval instar of the targeted pest was surface sterilized with $0.1 \%$ sodium hypochlorite before experimentation; after sterilization, these larvae were ready to use for bioassays.

\section{Isolation and culture of EPNs}

For the isolation of EPNs, a survey was conducted to collect the soil samples from the field of Beta vulgaris of the district Saharanpur, village Puwarka $\left(29.9888^{\circ}\right.$ $\mathrm{N}, 77.5870^{\circ} \mathrm{E} ; 276 \mathrm{~m}$ elevation), Uttar Pradesh, India. Soil samples were collected by adopting the technique of Wallace (1971) and were brought to the Nematology Laboratory in well-labeled polythene bags. The type of positive soil sample was sandy loam with $\mathrm{pH}$ 5.7. EPN was isolated from the soil samples using the Galleria baiting technique as described by Bedding and Akhurst (1975). Ten larvae of the baiting insect were placed at the bottom of each jar (250 ml, Borosil) containing $250 \mathrm{~g}$ moistened soil and covered with tissue paper and muslin cloths. Further the jars were placed in biological oxygen demand (BOD) at temperature $\left(27 \pm 2{ }^{\circ} \mathrm{C}\right)$. The jars were checked every day for larval mortality. Dead larvae from soil bait were collected, washed with double-distilled water (DDW), disinfected with $0.1 \%$ sodium hypochlorite solution and then placed onto White trap (White 1927) to collect the emerging IJs. The emerged IJs were harvested from White trap and stored in 175-ml culture flasks $\left(75 \mathrm{~cm}^{2}\right.$ Canted neck, Polystyrene, Non-pyrogenic, DNase/RNase, free sterile flask, Cat. No. 708001, Torson) in BOD at $15{ }^{\circ} \mathrm{C}$ for future use. Freshly emerged IJs were further used for experimentation.

\section{Morphological characterization}

To obtain the different generations of EPN for morphological studies, fully grown larvae of G. mellonella were infected with isolated IJs. Dead larvae were dissected on 3rd and 5th day after infection to collect the male 
and females of different generations. Adults of 1st and 2nd generation were collected separately, killed with hot Ringer's solution, fixed in TAF solution $(2 \mathrm{ml}$ triethanolamine, $7 \mathrm{ml}$ formalin, $91 \mathrm{ml}$ distilled water) (Courtney et al. 1955), dehydrated in Seinhorst (Seinhorst 1959) and then kept in glycerol. To prepare slides, nematodes were mounted onto a drop of glycerin and covered with coverslips which were sealed with paraffin wax. For morphological study, 20 IJs, 15 males (ôs) and 15 females (o's) of each generation were observed under light compound microscope (Magnus MLX) and phase-contrast microscope (Nikon Eclipse 50i). Morphometric analysis was carried out with the aid of in-built software of the phasecontrast microscope (Nikon DS-L1).

\section{Molecular characterization DNA isolation, amplification and sequencing}

For molecular studies, freshly emerged IJs were used to extract the Genomic DNA through Qiagen Blood \& Tissue Kit (Hilden, Germany) according to the manufacturer's protocol. Internal Transcribed Spacers (ITS) and $28 \mathrm{~S}$ ribosomal DNA (D2D3) were used for PCR amplification. The Internal Transcribed Spacers regions (ITS1, 5.8S, ITS2) of the rDNA were amplified using primers 18S: $5^{\prime}$-TTGATTACGTCCCTGCCCTTT-3' (forward) and 26S: $5^{\prime}$-TTTCACTCGCCGTTACTAAGG-3' (reverse) (Vrain et al. 1992). The rDNA fragment containing D2D3 regions of $28 \mathrm{~S}$ rDNA were amplified using primers (D2F): $5^{\prime}$-AGCGGAGGAAAAGAAACTAA- $3^{\prime}$ (forward) and (D3R): 5'-TCGGAAGGAACCAGCTACTA-3' (reverse) (Joyce et al. 1994). Briefly, PCR master mix consisted of Dream Taq Green PCR master mix 2X (Thermo Scientific) $15 \mu \mathrm{l}$, Nuclease free distilled water $10 \mu \mathrm{l}, 1 \mu \mathrm{l}$ of each forward and reverse primer, and $3 \mu \mathrm{l}$ of DNA extract contributing to a total volume of $30 \mu \mathrm{l}$. The cycling parameters were used as follows: for ITS: 1 cycle of $94{ }^{\circ} \mathrm{C}$ for $5 \mathrm{~min}$, followed by 35 cycles of $94{ }^{\circ} \mathrm{C}$ for $1 \mathrm{~min}$, annealing at $50{ }^{\circ} \mathrm{C}$ for $1 \mathrm{~min} 30 \mathrm{~s}$, primer extension at $72{ }^{\circ} \mathrm{C}$ for $1 \mathrm{~min}$ and a final extension at $72{ }^{\circ} \mathrm{C}$ for $15 \mathrm{~min}$, and for D2D3 fragment of $28 \mathrm{~S}$ rDNA: 1 cycle of $94{ }^{\circ} \mathrm{C}$ for $3 \mathrm{~min}$, followed by 35 cycles of $94{ }^{\circ} \mathrm{C}$ for $30 \mathrm{~s}, 52{ }^{\circ} \mathrm{C}$ for $30 \mathrm{~s}$, $72{ }^{\circ} \mathrm{C}$ for $1 \mathrm{~min}$ and a final extension at $72{ }^{\circ} \mathrm{C}$ for $10 \mathrm{~min}$. PCR was followed by gel electrophoresis $(45 \mathrm{~min}, 100 \mathrm{~V}$ ) of $5 \mu \mathrm{l}$ of PCR product in a 1\% TAE (Tris-acetic acidEDTA)-buffered agarose gel stained with ethidium bromide. The amplified products were purified and Sanger sequenced in both directions by Bioserve Technologies Ltd. (Hyderabad, India). The obtained forward and reverse sequences were aligned, edited and assembled using BioEdit (Hall 1999). Obtained sequencing results were submitted to the GenBank with accession numbers, MN527410 and MN528022 for ITS and D2D3 regions of Steinernema spp. isolate CS-39, respectively.

\section{Phylogenetic analyses}

Sequences of ITS and D2D3 regions of rDNA were matched with those already present in GenBank employing a Basic Local Alignment Search Tool (Altshul et al. 1990) of the National Centre for Biotechnology Information (NCBI). D2D3 region of $28 \mathrm{~S}$ and ITS is conservative in nature which helps in resolving the closely related Steinernema species. Their alignments created by default Clustal W parameters were figured using MEGA 7.0 (Kumar et al. 2016). The phylogenetic trees of the ITS and 28S rRNA were produced by the maximum likelihood method in MEGA 7.0 (Kumar et al. 2016). C. elegans was used as out-group taxa to root the trees.

\section{Median lethal concentration $\left(L C_{50}\right)$ at time period against $H$. armigera}

To determine the $\mathrm{LC}_{50}$ of nematode, an experiment was conducted using different concentrations of IJs viz., 25, 50, 100 and $200 \mathrm{IJ} /$ /arva along with the control group against the target pest $H$. armigera. To evaluate the pathogenicity of Steinernema spp. isolate CS-39, healthy larvae were used in bioassay experimentation. Tarson 6-well plates (well size $3.5 \mathrm{~cm}$ ) were used to conduct the experiment. Each well of these well plates was lined with double layer of Whatman Filter Paper No. 1. Different concentrations of IJs (25, 50, 100 and $200 \mathrm{IJ} /$ /larva) along with DDW were used to prepare the solution having a final volume of $400 \mu \mathrm{l}$. Prepared solution was poured into each well of well plates. For each concentration, 10 replicates were used along with a control group having DDW only. One larva per well was placed in above-prepared well plates and kept in BOD at $27 \pm 2{ }^{\circ} \mathrm{C}$. The larval mortality was recorded at different time intervals i.e., 36,48 and $60 \mathrm{~h}$ after inoculation. In order to confirm the exact cause of death, the dead larvae were dissected in Ringer's solution. Time mortality response of isolated Steinernema spp. CS-39 against the insect pest $H$. armigera was calculated by inoculating different concentrations, viz., 25 IJs/larva, $50 \mathrm{IJs} /$ larva, $100 \mathrm{IJs} /$ larva and $200 \mathrm{IJs} /$ larva, and observations were recorded at 12-h interval up to $60 \mathrm{~h}$.

\section{Statistical analysis}

Median lethal concentration $\left(\mathrm{LC}_{50}\right)$ was statistically analyzed by probit analysis using SPSS (version 20). The treatments of concentration and time were calculated using two-way ANOVA and means of treatment effect were compared by using Tukey multiple comparison test. To resolve the relationship between percent mortality and different concentrations of IJs/larva linear regression analysis was interpreted using the linear regression equation: $y=a+b x$ where $y$ is dependent variable (the percent mortalities of $H$. armigera at 24, 36, 48 and $60 \mathrm{~h}$ 
after different PIP) and $\mathrm{x}$ is independent variable (concentration of infective juveniles of Steinernema spp. isolate CS-39) with a as constant and b represents the slope. Linear regression analysis was performed using GraphPad Prism software.

\section{Results \\ Morphological characterization}

Morphological characters of different generations of present isolate were compared to original described species of S. abbasi (Elawad et al. 1997). The morphology was similar to the type population with only difference being the presence of mucron in second-generation male and female which was not observed in original description. It is considered as a member of "bicornutum group" due to the presence of two horn-like structure on cephalic region. Third-stage IJs were observed smaller in size when compared to IJs of already described species (Table 1). On comparing the present specimen with already described species of $S$. abbasi (Elawad et al. 1997), dissimilarity was observed only by presence of mucron in 2nd-generation male and female. The nerve ring in 1st- and 2nd-generation male of the present isolate was found to be at less distance above the basal bulb as compared to the described species (Table 1). As far as morphometry is concerned, a little alteration was observed in measurements, while most measurements were in close vicinity. The present isolate can be characterized by the third-stage IJs length 496 (344-552) $\mu \mathrm{m}$, "a" ratio 17 (14-19), "b" ratio $5.3(4.5-6.7)$ and tail 50 (33-63) $\mu \mathrm{m}$ (Table 2). The species was also recognized by 1st-generation male characters of $\mathrm{D} \% 69$ (60-96) and E\% 307 (261-447) and 1st-generation female characters of $\mathrm{D} \% 45$ (24-64) and E\% 183 (70-379), respectively (Table 2). First-generation male of the present specimen is characterized by slender and ventrally curved J-shaped body marked by lateral fields. Pharynx muscular with cylindrical procorpus, slightly swollen metacorpus and narrow isthmus. Distance from anterior end to excretory pore is always more than body width at excretory pore. Paired spicules and boat-shaped gubernaculum were observed. Tail short, bluntly conical without any terminal mucron, whereas second-generation male differed from the 1st generation by having smaller body size and presence of short mucron in tail region. First-generation female possesses prominent cheilorhabdions beneath the lips, smooth cuticle, indistinct lateral lines and phasmids. Well-developed cardia and nerve ring are just above the basal bulb. Vulva guarded with double-flapped epiptygmata and has transverse slit-like opening. Tail short, conoid with a pointed tip without mucron; on the other hand, 2nd-generation female possesses similar characters as of 1st-generation female except smaller length and tail more longer and sharply pointed with ventral post-anal swelling ending with a well-developed fine mucron. The little difference in morphological characters might be due to the diverse habitat and different climatic conditions. Morphometrics and comparative morphometrics with $S$. abbasi of all generations of present strain CS39 are presented in Tables 1 and 2, respectively.

\section{Molecular and phylogenetic analysis}

The phylogeny of the present isolate based on ITS rRNA does not show any variation with type populations of $S$. abbasi. In the flanking D2D3 domain of the 28S rDNA gene sequences also, the present isolate CS39 varies from the already described gene sequences by 4 bp and exhibited a clear monophyly of the group formed by the present isolates and described as S. abbasi MN527410 and MN528022, respectively (Figs. 1 and 2). BlastN analysis also showed that present isolates showed $99.89 \%$ similarity with type population. ITS and D2D3 evolutionary trees showed that the species of the 'bicornutum' group and present isolate CS39 formed a sister clad with all known species of 'bicornutum' group and formed a clear monophyletic clade of the group formed by the isolate CS39 with the S. kandii and other described species of $S$. abbasi.

\section{Median lethal concentration $\left(L C_{50}\right)$ at $24 \mathrm{~h}$ against $\mathrm{H}$. armigera}

$\mathrm{LC}_{50}$ is the number of nematodes required to cause half mortality of host $(H$. armigera). In probit analysis, the value of $\mathrm{LC}_{50}$ of present strain against $H$. armigera was $83.21 \mathrm{IJs} /$ larva after exposure at $24 \mathrm{~h}$, slope $0.2041 \pm 0.1260$. Mean mortality percentages of $H$. armigera larvae infected with $S$. abbasi isolate CS-39 at different concentrations are shown in (Table 3). The effect of the concentration (IJs/larva) $\left(\mathrm{F}_{(3,6)}=17.39\right.$, $p=0.002)$ and exposure of time $\left(\mathrm{F}_{(3,6)}=8.526\right.$, $p=0.014$ ) (Table 4 ) and interaction among each other (F $_{(9,18)}=2.816, p=0.029 ; 2$-way repeated-measure ANOVA) were found significant. It has been found that the 24-h post-infection period (PIP) of all the concentrations shows significantly less mortality than 36,48 and $60 \mathrm{~h}(p<0.0001$, Tukey's multiple comparison test, 2-way RM ANOVA). After $24 \mathrm{~h}$ of PIP, it was found that there were non-significant differences in percent mortalities of $\mathrm{H}$. armigera larvae between concentration of 25 and $50 \mathrm{IJs} /$ larva, while it was found significantly different from groups of one another. Mortality percent of larva at the concentration of 100 and 200 IJs/larva was significantly different from each other. After $36 \mathrm{~h}$ of PIP, the $25 \mathrm{IJs} /$ larva was not significantly different from 50 and $100 \mathrm{IJs} /$ larva concentrations. Also, $50 \mathrm{IJs} /$ larva concentration was non-significant from 100 IJs/larva; 


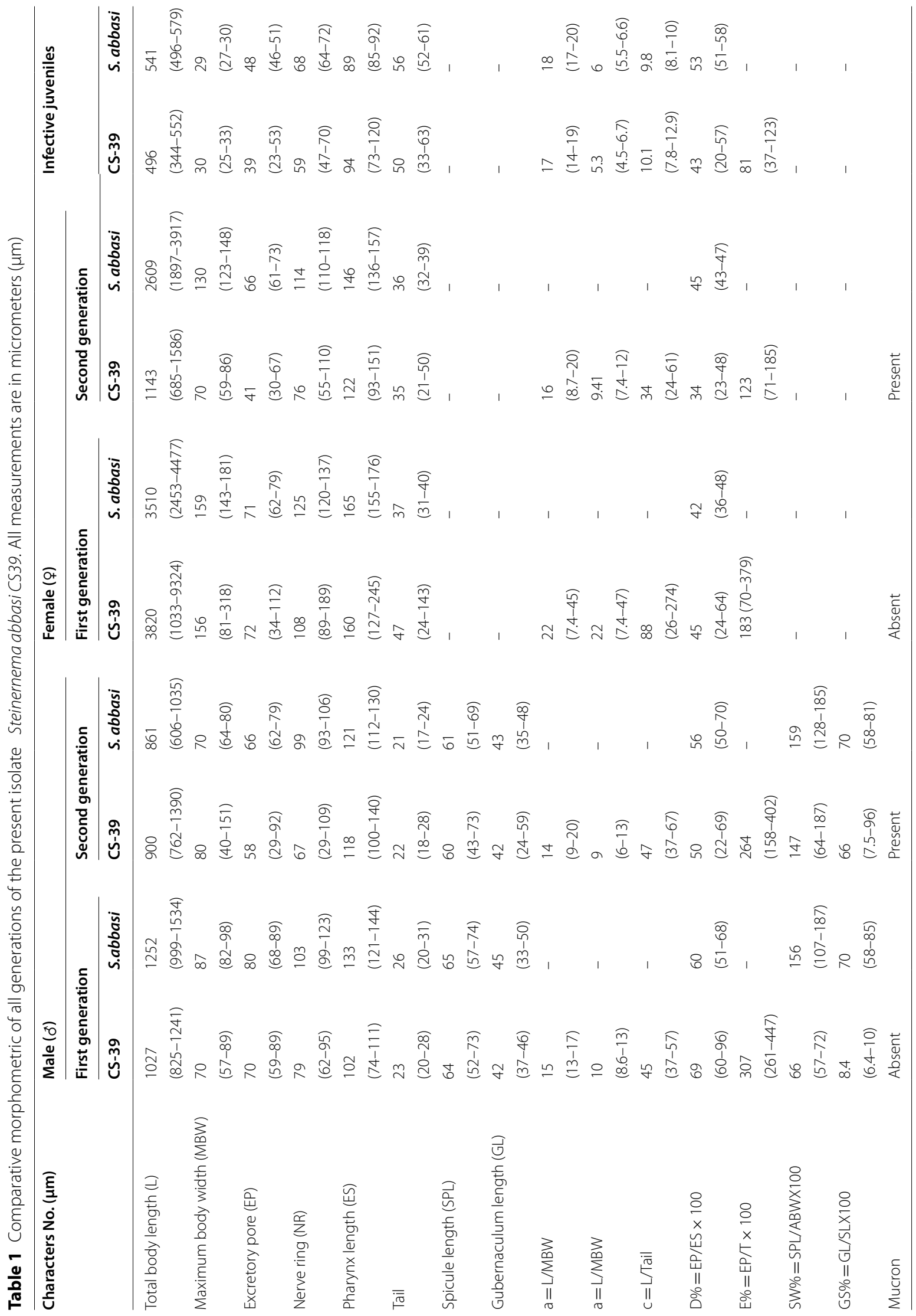


Table 2 Morphometric of all generations of isolate Steinernema abbasi CS-39. All measurements are in micrometer ( $\mu$ m) mean \pm standard deviation (range)

\begin{tabular}{|c|c|c|c|c|c|}
\hline \multirow[t]{2}{*}{ Characters no. $(\mu \mathrm{m})$} & \multicolumn{2}{|l|}{ First generation } & \multicolumn{2}{|l|}{ Second generation } & \multirow{2}{*}{$\begin{array}{l}\text { Infective Juveniles (IJs } \\
20\end{array}$} \\
\hline & $15 \delta^{\hat{2}}$ & $15 \%$ & 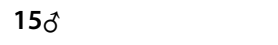 & $15 \%$ & \\
\hline Total body length (L) & $1027 \pm 106(825-1241)$ & $\begin{array}{l}3820 \pm 3070(1033- \\
9324)\end{array}$ & $1052 \pm 229(762-1390)$ & $1143 \pm 222(685-1586)$ & $496 \pm 55(344-552)$ \\
\hline $\begin{array}{l}\text { Maximum body width } \\
\text { (MBD) }\end{array}$ & $80 \pm 33(40-151)$ & $156 \pm 63(81-318)$ & $70 \pm 8.7(57-89)$ & $70 \pm 7.2(59-86)$ & $30 \pm 2.6(25-33)$ \\
\hline Excretory pore (EP) & $70 \pm 8.8(59-89)$ & $72 \pm 23(34-112)$ & $58 \pm 18(29-92)$ & $41 \pm 13(30-67)$ & $39 \pm 8.6(23-53)$ \\
\hline Nerve ring (NR) & $79 \pm 10(62-95)$ & $108 \pm 40(48-189)$ & $67 \pm 23(29-109)$ & $76 \pm 16(55-110)$ & $59 \pm 7.4(47-70)$ \\
\hline Pharynx length (ES) & $118 \pm 13(100-140)$ & $160 \pm 33(127-245)$ & $102 \pm 8.4(74-111)$ & $122 \pm 17(93-151)$ & $94 \pm 12(73-120)$ \\
\hline Anal body width (ABD) & $39 \pm 6.4(30-54)$ & $54 \pm 26(30-127)$ & $40 \pm 4.9(32-50)$ & $25 \pm 6.2(13-33)$ & $18 \pm 1.8(14-20)$ \\
\hline Tail & $23 \pm 2.0(20-28)$ & $47 \pm 30(24-143)$ & $22 \pm 3.1(18-28)$ & $35 \pm 8.8(21-50)$ & $50 \pm 8.5(33-63)$ \\
\hline $\mathrm{a}=\mathrm{L} / \mathrm{MBW}$ & $15 \pm 1.2(13-17)$ & $22 \pm 11(7.4-45)$ & $14 \pm 3.1(9-20)$ & $16 \pm 3.0(8.7-20)$ & $17 \pm 1.3(14-19)$ \\
\hline$b=L / E S$ & $10 \pm 1.1(8.6-13)$ & $22 \pm 14(7.4-47)$ & $9 \pm 2.0(6-13)$ & $9.4 \pm 1.4(7.4-12)$ & $5.3 \pm 0.6(4.5-6.7)$ \\
\hline $\mathrm{c}=\mathrm{L} /$ Tail & $47 \pm 7.6(37-67)$ & $88 \pm 73(26-274)$ & $45 \pm 5.7(37-57)$ & $34 \pm 9.2(24-61)$ & $10.1 \pm 1.3(7.8-12.9)$ \\
\hline Vulva (V) & - & $158 \pm 114(25-347)$ & - & $16 \pm 3(8.7-20)$ & - \\
\hline $\mathrm{D} \%=\mathrm{EP} / \mathrm{ES} \times 100$ & $69 \pm 10(60-96)$ & $45 \pm 11(24-64)$ & $50 \pm 13(22-69)$ & $34 \pm 8.9(23-48)$ & $43 \pm 11(20-57)$ \\
\hline $\mathrm{E} \%=\mathrm{EP} /$ Tail $\times 100$ & $307 \pm 50(261-447)$ & $183 \pm 85(70-379)$ & $264 \pm 72(158-402)$ & $123 \pm 35(71-185)$ & $81 \pm 23(37-123)$ \\
\hline Spicule length (SPL) & $64 \pm 5.0(52-73)$ & - & $60 \pm 7.4(43-73)$ & - & - \\
\hline
\end{tabular}

$\mathrm{n}=$ no. of specimens

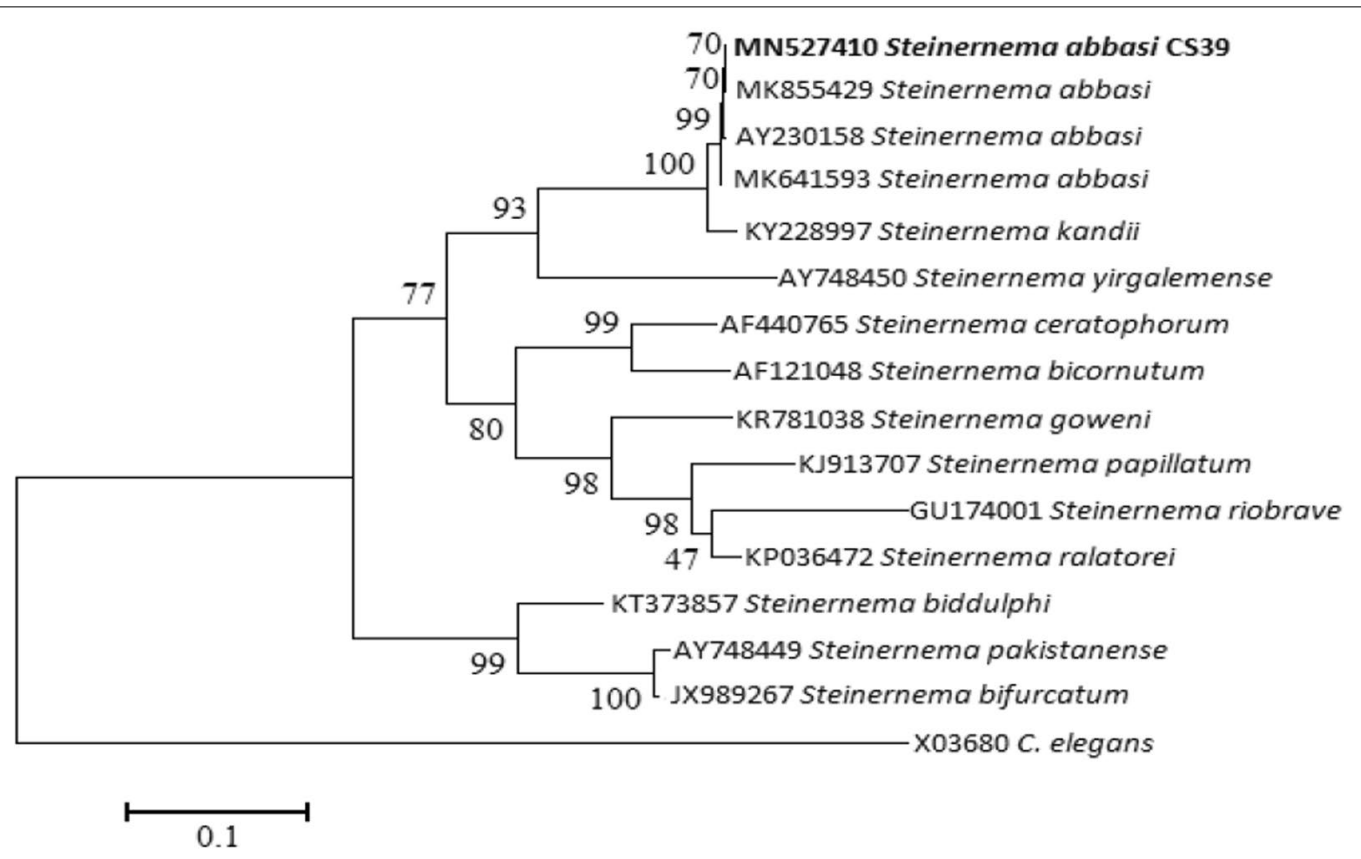

Fig. 1 Phylogenetic relationships in the "bicornutum" group of Steinernema based on analysis of ITS rDNA regions. Caenorhabditis elegans was used as outgroup taxa. The percentage of replicate trees in which the associated taxa clustered together in the bootstrap test (10,000 replicates) is shown next to the branches. Branch lengths indicate evolutionary distances and are expressed in the units of number of base differences per site

however, both 25 and 50 IJs/larva was significantly different from $200 \mathrm{IJs} /$ larva as it showed $100 \%$ mortality as compared to 76.66 and 83.33 under 25 and $50 \mathrm{IJs} /$ larva, respectively $(p<0.05$, Tukey's multiple comparison test). After $48 \mathrm{~h}$ of PIP, percent mortalities of H. armigera larvae at different concentrations of 25, 50, 100 


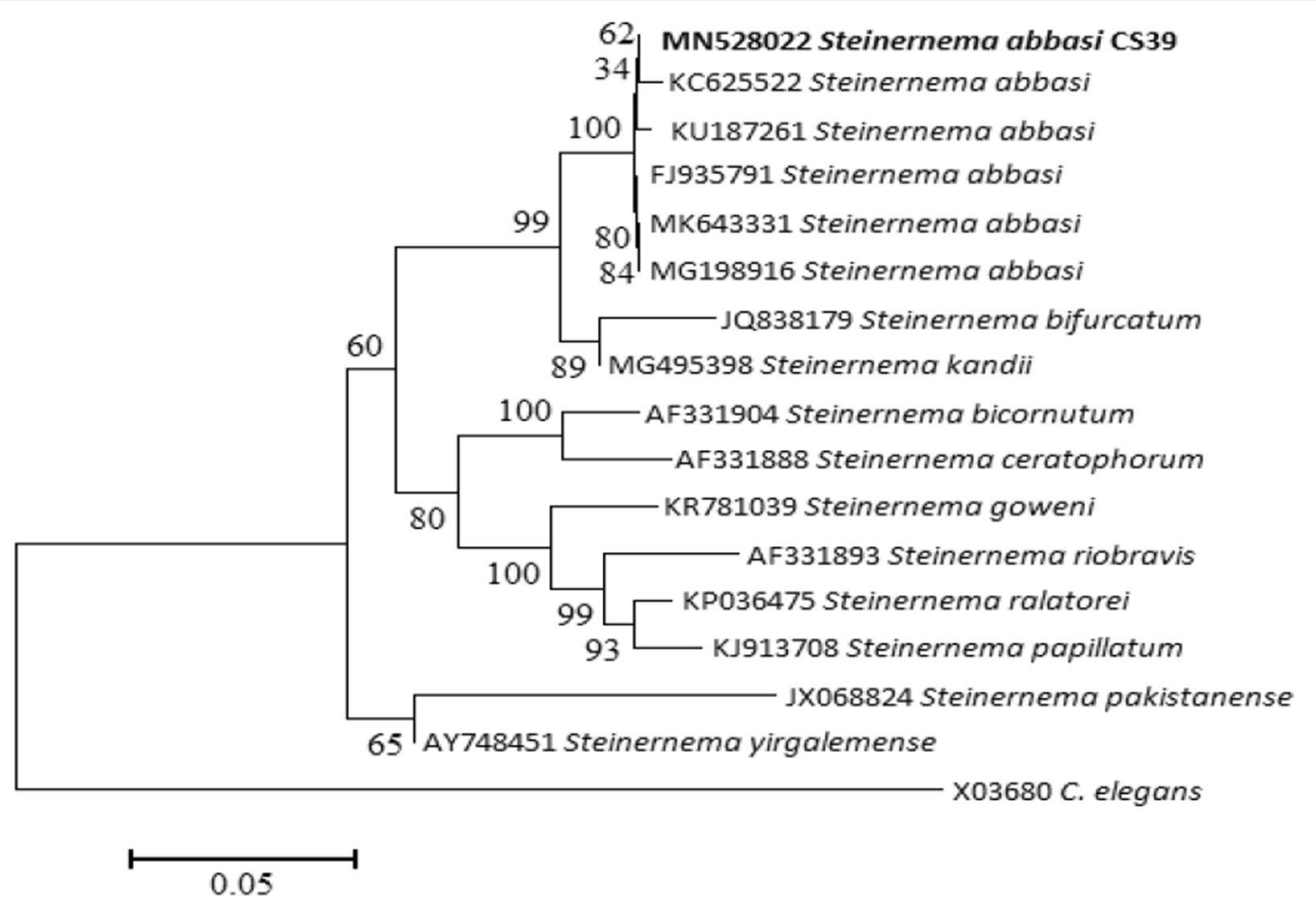

Fig. 2 Phylogenetic relationships in the "bicornutum" group of Steinernema based on analysis of D2D3 regions. Caenorhabditis elegans was used as outgroup taxa. The percentage of replicate trees in which the associated taxa clustered together in the bootstrap test (10,000 replicates) is shown next to the branches. Branch lengths indicate evolutionary distances and are expressed in the units of number of base differences per site

Table 3 Mean mortality percentages of Helicoverpa armigera larvae infected with isolate Steinernema abbasi (IJs) CS39 at different concentrations

\begin{tabular}{lllll}
\hline $\begin{array}{l}\text { Concentrations IJs } \\
\text { per larva }\end{array}$ & \multicolumn{4}{l}{$\begin{array}{l}\text { Mean mortality percentage of Helicoverpa } \\
\text { armigera larvae after different time of } \\
\text { infection (hrs) }\end{array}$} \\
\cline { 2 - 5 } & $\mathbf{2 4}$ & $\mathbf{3 6}$ & $\mathbf{4 8}$ & $\mathbf{6 0}$ \\
\hline 25 & 36.67 & 76.67 & 86.67 & 96.67 \\
50 & 36.67 & 83.37 & 90.00 & 96.67 \\
100 & 56.67 & 90.00 & 96.67 & 100 \\
200 & 70.00 & 100 & 100 & 100 \\
\hline
\end{tabular}

Table 4 Parameters assessed Mean mortality percentages of Helicoverpa armigera larvae infected with isolate Steinernema abbasi CS39 at different concentrations

\begin{tabular}{llll}
\hline Parameters & DF & F & $\boldsymbol{p}$ value \\
\hline Infective juveniles (IJS) & 3 & $F(3,6)=17.39$ & $p=0.0023$ \\
Time & 3 & $F(3,6)=8.526$ & $p=0.0139$ \\
Interaction of (IJs) and time & 9 & $F(9,18)=2.816$ & $p=0.0294$ \\
\hline
\end{tabular}

$\mathrm{DF}=$ degree of freedom; $\mathrm{F}=$ ratio of mean square and $200 \mathrm{IJs} /$ larva were found $86.67,90.00,96.67$ and 100 , respectively. At $60 \mathrm{~h}$ of PIP, non-significant differences were found in percent mortalities of $H$. armigera larvae at all the concentrations. Percent mortalities of $H$. armigera larvae at each concentration at $24,36,48$ and $60 \mathrm{~h}$ after infection were compared. It was found that percent mortalities at 25 and 50 IJs/ larva at 24 and $60 \mathrm{~h}$ were same and also, after $60 \mathrm{~h}$ of exposure $100 \%$ mortality achieved for the two concentrations 100 and $200 \mathrm{IJs} /$ larva (Table 3). After $24 \mathrm{~h}$ of infection, percent mortalities at the concentrations of 25, 50, 100 and $200 \mathrm{IJs} /$ larva were lower as compared to those at 36 , 48 and $60 \mathrm{~h}$ after infection, while these percentage at $36 \mathrm{~h}$ after infection were significantly lower than at $48 \mathrm{~h}$ and higher than those at $24 \mathrm{~h}$ of infection for each of the tested concentrations 25, 50, 100 and $200 \mathrm{IJs} /$ larva, respectively. Similarly, at $48 \mathrm{~h}$ after infection the concentrations of 25, 50, 100 and 200 IJs/larva were significantly lower than those $60 \mathrm{~h}$ and higher than the $36 \mathrm{~h}$ of infection at the different concentrations, respectively (Table 3).

According to \% mortality (in Table 4) calculate only $\mathrm{lc}_{50}$ iat $24 \mathrm{hrs}$ and mention it in text and then delete Table 3. 


\section{Linear regression analysis}

Results are obtained from linear regression analysis, and positive relationship was found between the concentration gradient and \% mortality at 36 and $48 \mathrm{~h}(p<0.05)$. However, no significance was found after 24 and $60 \mathrm{~h}$ $(p>0.05$ (Table 5 and Fig. 3)). Average to strong relationship existed between the concentration of IJs and exposure time at different PIP (coefficient of determination, $\mathrm{R}^{2}$, varied from 0.1409 to 0.4717 ).

The study of the present findings assessed the coefficient of determination $\left(R^{2}\right)$ that the $36 \mathrm{~h}(0.4717)$ and $48 \mathrm{~h}(0.4452)$ of exposure the infective juveniles of $S$. abbasi showed the moderate effect size, whereas $24 \mathrm{~h}$ (0.2078) and $60 \mathrm{~h}(0.1409)$ of exposure the infective juveniles of $S$. abbasi showed a very weak effect size and low effect size, respectively. The regression lines of percent mortality at various concentrations between 25 and 200 IJs per larva were:

$$
\begin{aligned}
& 24 \text { hrs } Y=0.2041 X+30.87(r=0.2078) \\
& 36 \text { hrs } Y=0.2041 X+75.65(r=0.4717) \\
& 48 \text { hrs } Y=0.0742 X+86.38(r=0.4452) \\
& 60 \text { hrs } Y=0.0209 X+96.38(r=0.1409)
\end{aligned}
$$

\section{Discussion}

The findings of the present investigation demonstrate the difference in perceptivity of $H$. armigera at different concentrations of CS-39 IJs/larva. The pathogenicity of EPNs in agreement with that of Sasnarukkit (2003) who reported that $\mathrm{LC}_{50}$ values for $S$. carpocapsae, S. siamkayai and $H$. bacteriophora after $60 \mathrm{~h}$ were 1.8, 52.5 and $59.1 \mathrm{IJs} /$ larva against diamondback moth, respectively. EPNs isolate belonging to the same species showed marked differences in pathogenicity have been previously documented by Tarasco et al. (2013). These differences in pathogenicity may be due to the soil habitats of these nematode species which play significant role in efficacy of EPNs isolates. This was quite obvious from the present

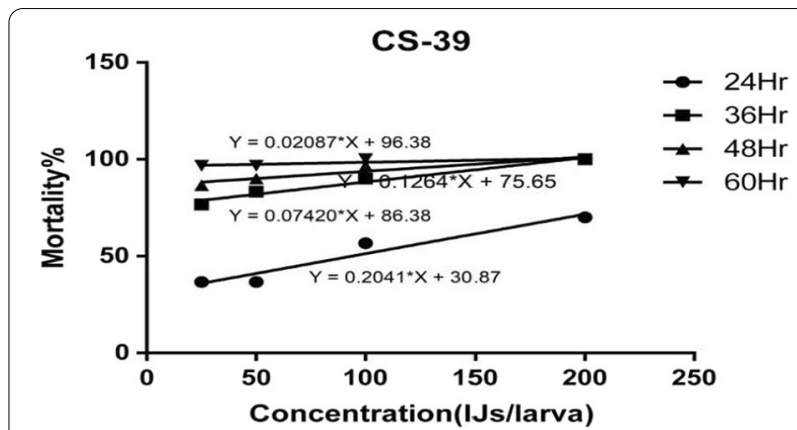

Fig. 3 Relationship between concentration of infective juveniles of Steinernema abbasi CS-39 and percent mortalities of Helicoverpa armigera at 24, 36, 48 and $60 \mathrm{~h}$ after infection.

study compared to the studies of earlier workers since the different type of nematode with different capacity to penetrate the insect would cause different results. It also showed that increasing the concentration and exposure time helped to increase the effective searching and infection chances of nematode. Glazer and Navon (1990) also reported the pathogenicity of EPNs against $H$. armigera larvae under laboratory conditions and found that the complete mortality was first achieved at $200 \mathrm{IJs} / \mathrm{larva}$, followed by other concentrations. The efficacy of $S$. abbasi on larvae of 3 different insect pests, viz., G. mellonella, $H$. armigera and Spodoptera litura, was tested under the laboratory conditions where the complete mortality was recorded at all the concentrations within $48 \mathrm{~h}$ of infection and it was found to be an excellent biocontrol agent against all these lepidopteran pests (Heena et al. 2021).

Molecular study of the present findings reveals that Steinernema kandii (Godjo et al. 2018) is much close to $S$. abbasi and in both trees sequences of $S$. abbasi populations, and this pair was sister to the Steinernema yirgalemense Nguyen et al. (2004) and Steinernema bifurcatum Fayyaz et al. (2014). However, S. abbasi showed clear demarcation from the $S$. kandii in the D2-D3 region and similar results were obtained in the ITS region also. Thus, based on morphological and molecular data supplemented with ITS and D2D3

Table 5 Mortality responses of Helicoverpa armigera larvae against an entomopathogenic nematode (Steinernema abbasi CS-39) at different time intervals

\begin{tabular}{llllll}
\hline Time (hrs) & Regression equation & $\mathbf{9 5 \%} \mathrm{Cl}$ & $\begin{array}{l}\mathbf{R}^{2} \text { Co-efficient of } \\
\text { determination }\end{array}$ & $\mathbf{F}$ & $\boldsymbol{p}$ value \\
\hline 24 & $Y=0.2041 X+30.87$ & -1.477 to 63.22 & 0.2078 & $2.624(1,10)$ & 0.1363 \\
36 & $Y=0.1264 X+75.65$ & 64.79 to 86.51 & 0.4717 & $\mathbf{8 . 9 3 ( 1 , 1 0 ) ^ { * * }}$ \\
48 & $Y=0.07420 X+86.38$ & 79.65 to 93.10 & 0.4452 & $\mathbf{8 . 0 2 5}(\mathbf{1 , 1 0})^{* *}$ & $\mathbf{0 . 0 1 3 6 ^ { * * }}$ \\
60 & $Y=0.02087 X+96.38$ & 92.19 to 100.6 & 0.1409 & $1.64(1,10)$ & 0.2293 \\
\hline
\end{tabular}

Bold values represent statistical significance $(p<0.05)$

**Significant 
rDNA gene sequences proved the position of the isolate CS39 species of $S$. abbasi according to the phylogenetic and evolutionary species concept (Adams 1998).

Linear regression analysis showed that the IJs concentration of S. abbasi CS-39 was in positive correlation with percent larval mortalities of $H$. armigera larvae. This meant that percent mortality of $H$. armigera increased with increasing the concentrations of nematode. The results revealed that longer exposure of IJs made possible for more nematodes to penetrate in G. mellonella larvae and more release of the bacterial metabolites inside the insect body. The results validated with the finding of Caroli et al. (1996) in which they reported the complete mortality of G. mellonella within 24-72 h of exposure. Mortality $(100 \%)$ of $H$. armigera larvae was achieved at the inoculum level of $100 \mathrm{IJs} /$ larva at $60 \mathrm{~h}$ of exposure.

\section{Conclusions}

It was concluded that $H$. armigera larvae were highly perceptible to different concentrations of $S$. abbasi CS-39 infection, causing complete mortality of the insect pest. More IJs per larva was required to kill the pest in less time; on the other hand, more exposure of time was required to achieve the $100 \%$ mortality at less concentration. It is inferred from the study that the described species of entomopathogenic nematode, $S$.abbasi is pathogenic and more virulent to $H$. armigera larvae which shows that the isolate CS39 has good biocontrol potential on insect pest $H$. armigera. This study opens the new parkway to work on utilization of this potent biocontrol agent in field trials against various lepidopteran pests infesting field crops, which is mostly chemical dependence. Further researches are still needed before recommending the strain to be applied.

\begin{abstract}
Abbreviations
EPN: Entomopathogenic nematode; EPB: Entomopathogenic bacteria; IJs: Infective juveniles; DDW: Double-distilled water; PIP: Post-infection period; LC: Lethal concentration; Cl: Confidence interval; IPM: Integrated pest management; DF: Degree of freedom; PCR: Polymerase chain reaction; ITS: Internal transcribed spacers; H: Hour; B: Biological oxygen demand; TAF: Triethanolamine; DNA: Deoxyribose nucleic acid; TAE: Tris-acetic acid-EDTA; D2D3: Domain2 Domain3; MEGA: Molecular evolutionary genetics analysis; ABW: Anal body width.
\end{abstract}

\section{Acknowledgements}

The authors are thankful to the Head of the Department of Zoology, Chaudhary Charan Singh University, Meerut, for providing necessary laboratory facilities for conducting the experiments.

\section{Authors' contributions}

The study was designed by SS and AKC. Interpretation of the data was done by SS. Manuscript writing was done by all authors. Tables and reference settings were done by $\mathrm{H}$. Errors and grammatical mistakes in manuscript were removed and edited by AKC. Then, final manuscript was read and approved by all authors. All authors read and approved the final manuscript.
Funding

There are no funding sources for this manuscript.

Availability of data and materials

The data and material of this manuscript are available from corresponding author on reasonable request.

\section{Declarations}

Ethics approval and consent to participate

This article does not contain any studies with human participants or animals.

Consent for publication

Not applicable.

\section{Competing interests}

The authors declare that they have no competing interests.

Received: 8 November 2021 Accepted: 31 January 2022

Published online: 05 February 2022

\section{References}

Abd-Elgawad MMM (2021) Optimizing sampling and extraction methods for plant-parasitic and entomopathogenic nematodes. Plants 10:629

Adams BJ (1998) Species concept and evolutionary paradigm in modern nematology. J Nematol 30:1-21

Altschul SF, Gish W, Miller W, Myers EW, Lipman DJ (1990) Basic local alignment search tool. J Mol Biol 215:403-410

Bedding RA, Akhurst RJ (1975) A simple technique for the detection of insect parasitic rhabditid nematodes in soil. Nematologica 21:109-110

Benseddiq Y, Benseddik Y, Joutei AB, Blenzar A, Dababat AA (2020) Occurrence and distribution of entomopathogenic nematodes (Steinernematidae and Heterorhabditidae) in Morocco. Biocontrol Sci Technol 30:1060-1072

Cabanillas EH, Raulston JR (1994) Pathogenicity of Steinernema riobravis against corn earworm Helicoverpa zea (Boddie). Fundam Appl Nematol 17:219-223

Canhilal R, Waeyenberge L, Toktay H, Bozbuga R, Çetintas R, Imren M (2016) Distribution of Steinernematids and Heterorhabditids (Rhabditida: Steinernematidae and Heterorhabditidae) in the southern Anatolia region of Turkey. Egypt J Biol Pest Co 26(4):1-6

Caroli L, Glazer I, Gaugle R (1996) Entomopathogenic nematode infectivity assay: comparison of penetration rate into different hosts. Biocontrol Sci Technol 6(2):227-234

Courtney WD, Polley D, Miller VI (1955) TAF an improved fixative in nematode technique. Plant Dis Rep 39:570-571

Dillman AR, Chaston JM, Adams BJ, Ciche TA, Goodrich-Blair H, Patricia S, Sternberg PW (2012) An entomopathogenic nematode by any other name. PLOS Pathog 8:e1002527

Elawad SA, Ahmad W, Reid A (1997) Steinernema abbasi sp. n. (Nematode: Steinernematidae) from the Sultanate of Oman. Fundam Appl Nematol 20:433-442

Epsky ND, Capinera JL (1994) Invasion efficiency as measure of efficacy of the entomogenous nematode Steinernema carpocapsae (Rhabditida: Steinernematidae). J Econ Entomol 87:366-370

Fayyaz S, Yan X, Qiu L, Han R, Gulsher M, Khanum TA, Javed S (2014) A new entomopathogenic nematode, Steinernema bifurcatum n. sp. (Rhabditida: Steinernematidae) from Punjab Pakistan. Nematology 16(7):821-836

Glazer I, Navon A (1990) Activity and persistence of entomogenous nematodes used against Heliothis armigera (Lepidoptera: Noctuidae). J Econ Entomol 83:1795-1800

Godjo A, Afouda L, Baimey H, Couvreur M, Zadji L, Houssou G (2018) Steinernema kandii n. sp. (Rhabditida: Steinernematidae), a new entomopathogenic nematode from northern Benin. Nematology 21(2):1-22

Grewal PS, Selvan S, Gaugler R (1994) Thermal adaptation of entomopathogenic nematodes - niche breadth for infection, establishment and reproduction. J Therm Biol 19:245-253 
Hall TA (1999) BIOEDIT: A user-friendly biological sequence alignment editor and analysis program for windows 95/98/ NT. Nucleic Acids Symp Ser 41:95-98

Heena, Rana A, Bhat AH, Chaubey AK (2021) Morpho-taxometrical and molecular characterization of Steinernema abbasi (Nematoda: Steinernematidae) and its pathogenicity and generative potential against lepidopteran pests. Egypt J Biol Pest Control 31: 21 (2021). https://doi org/10.1186/s41938-020-00359-1.

Joyce SA, Reid A, Driver F, Curran J (1994) Application of polymerase chain reaction $(P C R)$ methods to the identification of entomopathogenic nematodes. In: Burnell AM, Ehlers R-U, Masson JP (eds) COST 812 Biotechnology: genetics of entomopathogenic nematode-bacterium complexes, Proceedings of symposium \& workshop, St. Patrick's College, Maynooth, Co. Kildare, Ireland. European Commission, DG XII, Luxembourg, pp 178-187

Kalia V, Chaudhari S, Gujar GT (2001) Optimization of production of nucleopolyhedrovirus of Helicoverpa armigera throughout larval stages. Phytoparasitica 29:23-28

Kepenekci I, Hazir S, Oksal E, Lewis EE (2018) Application methods of Steinernema feltiae, Xenorhabdus bovienii and Purpureocillium lilacinum to control root-knot nematodes in greenhouse tomato systems. Crop Prot 108:31-38

Kumar S, Stecher G, Tamura K (2016) MEGA7: molecular evolutionary genetics analysis version 7.0 for bigger datasets. Mol Biol Evol 33(7):1870-1874

Majić I, Sarajlić A, Lakatos T, Tóth T, Raspudić E, Puškadija Z, Kanižai ŠG, Laznik $\check{Z}$ (2019) Virulence of new strain of Heterorhabditis bacteriophora from Croatia against Lasioptera rubi. Plant Protect Sci 55:134-141

Nagarkatti S, Prakash A (1974) Rearing Heliothis armigera (Hubn.) on artificial diet Commonwealth Institute of Biological Control, Bangalore. Tech Bull 17:169-173

Nguyen KB, Tesfamariam M, Gozel U, Gaugler R, Adams B (2004) Steinernema yirgalemense $n, s p$. (Rhabditida: Steinernematidae) from Ethiopia. Nematology 6(6):839-856

Sasnarukkit A, Gaugler R, Sontirat S (2003) Pathogenicity of entomopathogenic nematodes against diamondback moth larvae (Plutella xylostella $\mathrm{L})$ at different dosages, temperatures and moistures. Thai J Agric Sci 36(4):441-451

Seinhorst JW (1959) A rapid method for the transfer of nematodes from fixative to anhydrous glycerin. Nematologica 4:67-69

Stacke RF, Arnemann J, Rogers J, Stacke RS, Strahl TT, Perini CR, Dossin MF, Pozebon H, Cavallin LA, Guedes JVC (2018) Damage assessment of Helicoverpa armigera (Lepidoptera: Noctuidae) in soybean reproductive stages. Crop Prot 112:10-17

Tarasco E, Triggiani O (2016) Survey of steinernema and heterorhabditis (rhabditida: nematoda) in Southern Italian soils. Entomologica 31:117-123

Tay WT, Soria MF, Walsh T, Thomazoni D, Silvie P, Behere GT, Anderson C, Downes S (2013) A brave new world for an old-world pest: Helicoverpa armigera (Lepidoptera: Noctuidae) in Brazil. PLoS ONE 8:e80134. https:// doi.org/10.1371/journal.pone.0080134

Vos JG, Dybing E, Greim HA, Ladefoged O, Lambre C, Tarazona JV, Brandt I, Vethaak AD (2000) Health effects of endocrine-disrupting chemicals on wildlife, with special reference to the European situation. Crit Rev Toxicol 30:71-133

Vrain T, Wakarchuk D, Levesque A, Hamilton R (1992) Intra-specific rDNA restriction fragment length polymorphism in the Xiphinema americanum group. Fundamental Appl Nematol 15(6):563-573

Wallace HR (1971) Plant parasitic nematodes. In: Zukerman BM, Mai WM, Rohde RA (eds). Academic Press, New York, vol 1, pp 257-280

White GF (1927) A method for obtaining infective nematode larvae from cultures. Science 66:302-303

Yuksel E, Canhilal R (2018) Evaluation of local isolates of entomopathogenic nematodes for the management of black cutworm, Agrotis ipsilon Hufnagel (Lepidoptera: Noctuidae). Egypt J Biol Pest Cont 28(1):82

\section{Publisher's Note}

Springer Nature remains neutral with regard to jurisdictional claims in published maps and institutional affiliations.

\section{Submit your manuscript to a SpringerOpen ${ }^{\odot}$ journal and benefit from:}

- Convenient online submission

- Rigorous peer review

- Open access: articles freely available online

- High visibility within the field

- Retaining the copyright to your article

Submit your next manuscript at $\mathbf{s p r i n g e r o p e n . c o m ~}$ 